\title{
EDITORIAL
}

\section{Looking Beyond the International: Key Themes and Approaches of Transnational Environmental Law}

It is a pleasure for us to write as members of the editorial board of the new journal, Transnational Environmental Law. We are very grateful to Thijs Etty and to Veerle Heyvaert for the enormous amount of work they have done to produce this exemplary first issue. It contains papers by some of the most exciting talent in environmental law and the range of topics and approaches that these papers encompass testifies to the breadth and vigour of the concept of transnational environmental law. The journal has active support from its outstanding advisory board and the quality of the individuals who make up this board speaks volumes about the importance and timeliness of a new journal of this kind.

As many of the contributors to this volume emphasize, the language of the 'transnational' is useful and appropriate, perhaps in part because its meaning is contested and its boundaries unclear. As Greg Shaffer, a contributor to this volume, has said elsewhere: '[a]lthough the terms transnational law and state transformations are increasingly used, we need clearer conceptual work and more empirical study'. ${ }^{1}$ This is precisely what this journal is about, and it is hoped that reflection will focus upon the notion of the transnational and upon the influence of this upon our evolving understanding of law. A broad conception of the transnational sphere tends to go hand in hand with a correspondingly broad conception of what counts as law.

While concepts do not have an inherent meaning, over time they tend to become strongly imbued with certain characteristics. Thus, the term 'international' tends to be associated with interstate relations within the framework of international organizations and treaty regimes. International organizations and treaties form an important part of the terrain of transnational law but they do not exhaust it. On the contrary, the concept of transnational law is intended to provide space to acknowledge the proliferation of sites of governance and of the actors that steer behaviour beyond the boundaries of a single state. This includes state and sub-state actors but, importantly, non-state actors as well.

The contours and complexity of transnational law can be captured in the area of climate change. With Keohane and Victor's now famous concept of a climate change

1 G. Shaffer, 'Transnational Legal Process and State Change: Opportunities and Constraints', Minnesota Legal Studies Research Paper No. 10-28, available at: http://ssrn.com/abstract=1901952. 
regime complex the governance landscape was already challenging and dense. ${ }^{2}$ They highlighted that climate change governance operates at many levels and in functionally differentiated spheres. Then Kenneth Abbott came along with his highly informative 'transnational climate change governance triangle, involving 67 acronyms, three vertexes, three tiers, seven zones and variegated governance combinations between civil society, states and firms' $!^{3}$

The complexity of the governance landscape presents a challenge for both scholars and for policy-makers. This is a descriptive (or data) challenge and a normative (or legitimacy) challenge as well. For lawyers, the phenomenon of transnational governance is exciting but also destabilizing. We are not quite as certain today that we know what to count as law or that law is inherently tied to the state. Our methodologies for identifying and constructing law have also started to change. In the world of transnational law and governance, we can no longer simply read law off the statute book or case report. We have to examine multifarious institutional practices as well.

We have been asked to introduce four of the pieces that follow: the papers by Gunningham, Brown Weiss, Streck, and Gillespie, which in turn look at energy law, water protection law, climate change law, and conservation law.

Neil Gunningham is one of the world's leading scholars on regulation and governance and his paper provides a fantastic example of the kind of thinking that led to the creation of the journal. His starting point is that an 'energy revolution' will be required if a transition to a low carbon economy is to be achieved. ${ }^{4} \mathrm{He}$ presents energy law and governance as one of the most pressing environmental, political and social challenges of our time. But he observes that existing global institutions for energy governance are weak, fragmented and often non-inclusive in relation to poor and developing states. The challenge of energy security prevents realist states from cooperating in an emphatic and effective way. One consequence of this is that, despite much talk of 'green finance', no sources of funding remotely commensurate with the energy challenge have yet been found.

For Gunningham this provides a starting point for a research challenge which exemplifies the notion of transnational environmental law. His aim is to look beyond the international conceived as inter-governmental to the transnational conceived in a more open and flexible way. One of the key features of this more flexible approach is that multiple levels of governance as well as private actors are brought in. Transnational energy law and governance would focus not just on international institutions, for example under the rubric of the United Nations (UN) or the Organization for Economic Co-operation and Development (OECD). It would also focus upon markets, networks and private standards. Neil Gunningham readily acknowledges that

2 R.O. Keohane \& D.G. Victor, 'The Regime Complex for Climate Change' (2011) 9 Perspectives on Politics, pp. 7-23.

3 K. Abbott, 'The Transnational Regime Complex for Climate Change', Apr. 2011, available at: http://media.cigionline.org/geoeng/2010\%20-\%20Abbott\%20-\%20The\%20Transnational\%20Regime\% 20 Complex $\% 20$ for $\% 20$ Climate $\% 20$ Change.pdf.

4 N. Gunningham, 'Confronting the Challenge of Energy Governance' (2012) 1(1) Transnational Environmental Law, pp. 119-35. 
there is much work to be done 'to map the sorts of informal networks and other nonstate mechanisms that might form the "glue" for this form of governance'.

In this, Gunningham echoes a broader point made by David Kennedy about the 'mystery of global governance', emphasizing just how little we actually know. ${ }^{6}$ For the editors of this journal, this empirical dimension is of key importance. Our theoretical perspectives need to be built up, tested and revised on the basis of a deep and reflexive understanding of circumstances on the ground. The way in which theories of global administrative law have developed is a good example in this respect, ${ }^{7}$ as are the concepts of new governance or democratic experimentalism which have their roots in changing patterns of governance and use these to interrogate our understanding of law. ${ }^{8}$ Elizabeth Fisher is surely right when she cautions against wishful thinking dressed up as empirical investigation, ${ }^{9}$ but as Fisher herself would readily accept, theoretical reflection without sustained empirical engagement is a dangerous form of wishful thinking as well.

A leading authority on international law and natural resources law, Edith Brown Weiss, has made notable contributions to the practice as well as the study of international law. Her contribution sounds a clarion call for action to address the 'coming water crisis'. ${ }^{10}$ Just as Gillespie's contribution on international conservation law illustrates the close relationship between science and law, ${ }^{11}$ Brown Weiss' contribution underlies the importance of understanding the scientific aspects of water in order to craft legal solutions to water problems. The paucity of data on ground water aquifers, and policy failure to consider the scientific characteristics of the hydrological cycle, for example, have led to severe mismanagement of scarce water resources.

Water has traditionally been conceived as a local or regional resource in law. Most multilateral and bilateral water agreements focus on a particular water body, river basin system or sea. ${ }^{12}$ Domestic laws dealing with water supply and water pollution are in place in many states. Brown Weiss argues, however, that water should no longer

5 Ibid., at 133.

6 D. Kennedy, 'The Mystery of Global Governance', in J. Dunoff \& J. Trachtman, Ruling the World: Constitutionalism, International Law and Global Governance (Cambridge University Press, 2009).

7 See B. Kingsbury, N. Krisch \& R. Stewart, 'The Emergence of Global Administrative Law' (2004-2005) 68 Law \& Contemporary Problems, pp. 15-61, at 16.

8 For examples in the EU context see C.T. Sabel \& J. Zeitlin (eds.), Experimentalist Governance in the European Union: Towards a New Architecture (Oxford University Press, 2010).

9 E. Fisher, 'The Rise of Transnational Environmental Law and the Expertise of Environmental Lawyers' (2012) 1(1) Transnational Environmental Law, pp. 43-52, at 47.

10 E. Brown Weiss, 'The Coming Water Crisis: A Common Concern of Humankind' (2012) 1(1) Transnational Environmental Law, pp. 153-68.

11 A. Gillespie, 'Science, Values and People: The Three Factors that Will Define the Next Generation of International Conservation Agreements' (2012) 1(1) Transnational Environmental Law, pp. 169-82.

12 Examples of multilateral water agreements include the Agreement on the Cooperation for the Sustainable Development of the Mekong River Basin, Convention on the Protection of the Rhine, and the African Convention on the Conservation of Nature and Natural Resources. On bilateral water agreements, Singapore and Malaysia have signed four agreements to regulate the supply of water from Malaysia to Singapore (which meets about half of the latter's water demand): Y. Kog, et al., Beyond Vulnerability? Water in Singapore-Malaysia Relations (Singapore Institute of Defence and Strategic Studies, Nanyang Technological University, 2002). 
be conceived as a purely domestic concern. Environmental factors, the politics of power and money render it necessary to redefine water as a transnational concern. Brown Weiss points to these key global developments to support this proposition: increased global access to hydrological data and the need to put in place arrangements to ensure effective and equitable access; virtual water transfers; foreign land and water acquisitions by water-scarce countries to grow crops which can be exported back to their countries to feed their populations. Brown Weiss argues that if we were to recognize the availability and use of water resources as a 'common concern of humankind', it would provide a normative basis for the international community to address a range of water-related problems in areas ranging from agriculture to foreign investment law.

Similar to climate change and biological diversity, which have been declared a 'common concern of humankind', water issues require global negotiation but the solutions will be largely rooted in local action. This points to often neglected aspects of the transnational policy discourse - the sub-national tier of territorial government and the importance of 'bottom-up' law-making originating from within states, based on their institutional, technological, economic and political capacities. The 'bottom-up' approach could refer to a mode of creating treaty architecture. Bodansky's writings on the architecture of the international climate change regime provide an example. ${ }^{13}$ The 'bottom-up' approach could also refer to policies designed and implemented at the lowest feasible level of organization. It abandons the idea that water policy, for example, requires a universal framework or needs to be fitted into a formal global agreement for action. Steve Rayner celebrates the revival of such thinking in policy discourse. ${ }^{14}$ Finally, as Janet Koven Levit explains:

the 'bottom-up' label grounds the normative process in the practitioners, both public and private ... who join with others ... to share experiences and standardize practices towards shared goals ... Second, the 'lawmaking' label punctuates the flow from informal norm to hard (or harder) law. ${ }^{15}$

All three definitions or propositions exemplify different facets of the notion of transnational law and, bringing the discussion back to Brown Weiss' contribution, point to different ways of framing the analysis of how the language of 'common concern of humankind' can galvanize law-making to address the 'coming water crisis'.

Charlotte Streck combines her experience as a consultant to governments and companies with her analytical skills to produce a prolific body of scholarship on the

13 D. Bodansky, 'Targets and Timetables: Good Policy but Bad Politics', in J.E. Aldy \& R.N. Stavins (eds.), Architectures for Agreement: Addressing Global Climate Change in the Post-Kyoto World (Cambridge University Press, 2007), pp. 57-66; D. Bodansky, 'The Future of Climate Governance: Creating a More Flexible Architecture', in R.B. Stewart, B. Kingsbury \& B. Rudyk (eds.), Climate Finance: Regulatory and Funding Strategies for Climate Change and Global Development (New York University Press, 2010), pp. 48-56.

14 S. Rayner, 'How to Eat an Elephant: A Bottom-up Approach to Climate Policy' (2010) 10 Climate Policy, pp. 615-21.

15 J. Levit, 'Bottom-Up International Lawmaking: Reflections on the New Haven School of International Law' (2007) 32 Yale Journal of International Law, pp. 393-420, at 409. 
legal aspects of carbon trading. Streck's scholarship is an instructive example of bringing theory and practice together to generate innovative ideas and knowledge. In her contribution, she has chosen three case studies to illustrate the limits and potential of international law to address climate change. ${ }^{16}$ The implementation of the Kyoto Protocol mechanisms (emissions trading, the Clean Development Mechanism (CDM) and Joint Implementation) constitutes one of the examples. ${ }^{17}$ In the process of creating this international carbon market, the Kyoto Protocol regime has elaborated and refined rules on how to measure, account for and transfer emissions rights and allowances, thereby serving as a standard-setter for voluntary carbon markets, domestic emissions trading schemes, and regional schemes such as the European Union (EU) Emissions Trading Scheme (ETS). ${ }^{18}$ Streck points out that the road to implementation of the Kyoto Protocol mechanisms has been rocky mainly because rules have been developed in a pragmatic rather than considered manner. The lack of analysis underpinned by a strong normative basis often resulted in poor decisions. For example, the bodies set up to administer the market mechanisms turned out to be illequipped to deal with private sector concerns such as the lack of due process and exposure to poorly justified decisions that had significant ramifications for investment strategies. This is a prime example of global administrative law in practice. As transnational law seeks to involve private actors in law-making and implementation, it must also become more responsive to private sector concerns. How this should be done must be the subject of careful deliberation guided by universally accepted principles such as legitimacy, broad participation, and equity.

Streck is emphatic that international law and the UNFCCC regime ${ }^{19}$ can only contribute so much to addressing climate change, which requires action from all sectors and actors in the global economy. ${ }^{20}$ This is both a humbling reminder as well as a word of encouragement. On one hand, it is an apt reminder that legal processes and solutions can play an important albeit limited role. ${ }^{21}$ On the other hand, transnational law embraces the call to take a much broader view of how practices and behaviours gel as 'law', and how the international community can create the right incentives to encourage practical cooperation among large greenhouse gas emitters to control their emissions, support the formation of regional collaboration, and so on.

Alexander Gillespie brings to bear his considerable academic and practical experience in writing about science, values and people in the context of international

16 C. Streck, 'Innovativeness and Paralysis in International Climate Policy' (2012) 1(1) Transnational Environmental Law, pp. 137-52.

17 Kyoto Protocol to the United Nations Framework Convention on Climate Change, Kyoto (Japan), 10 Dec. 1997, in force 16 Feb. 2005, available at: http://unfccc.int/kyoto_protocol/items/2830.php.

18 Directive 2003/87/EC establishing a Scheme for Greenhouse Gas Emission Allowance Trading within the Community and amending Council Directive 96/61/EC [2003] OJ L275/32, as amended.

19 United Nations Framework Convention on Climate Change (UNFCCC), New York, NY (US), 9 May 1992, in force 21 Mar. 1994, available at: http://unfccc.int.

20 See also C. Streck, 'Struggling with Expectations and Changing Realities: International Climate Negotiations' (2012) 21(1) Journal of Environment \& Development, pp. 52-6.

21 See, e.g., P. Newell, 'Climate Change, Human Rights and Corporate Accountability', in S. Humphreys (ed.), Human Rights and Climate Change (Cambridge University Press, 2009), pp. 126-58. 
conservation law. ${ }^{22}$ Gillespie illustrates the two-way relationship between science and law. While changing scientific understandings of how to classify species do and should impact upon law, so too must law shape the framework in which scientific inquiry occurs. Any 'solution' to the challenge of classifying species must rest, Gillespie emphasizes, upon 'a flexible approach where nomenclature is both evolving and may be subject to change'. ${ }^{23}$

While Gillespie's article is about 'international' conservation agreements, nonetheless the transnational dimension slips in. For example, Gillespie examines the important role of the International Union for the Conservation of Nature and Natural Resources (IUCN) in classifying natural sites of importance as protected areas. The IUCN is an organization which comprises over 1,000 members, 11,000 scientific experts in thematic commissions and over 1,000 staff, drawn from all over the world. ${ }^{24}$ It includes over 800 nongovernmental organizations (NGOs) and close to 100 international NGOs, as well as states and government agencies. This gives the IUCN 'a neutral and convening power when gathering governments and civil society. ${ }^{25}$ The IUCN is a public-private hybrid that generates transnational environmental law, and IUCN law interacts with more traditional forms of law. To give just one example, the EU draws upon the IUCN's classification of protected sites for the purpose of implementing its sustainability criteria for biofuels. ${ }^{26}$

The story that Gillespie tells in his article shares common ground with Neil Gunningham's account: 'Despite there now being a clear international consensus that it is necessary to secure the variety of life on Earth, there is no international convention for the protection of animals per se ${ }^{27}$ Governance in relation to nature conservation is multilevel, fluid, fragmented and incomplete.

Gillespie's paper makes clear the important role of international law in shaping governance arrangements within nation states. This is a key element of transnational environmental law. He offers the example of public participation, including the participation of indigenous peoples. He points out that conservation efforts that eschew engagement with local people are prone to fail. Using the example of the World Heritage Convention ${ }^{28}$ of which Gillespie was Rapporteur, he points out that the World Heritage Committee has emphasized the importance of local participation and the need to share the profits of conservation activities with local communities. At every turn in Gillespie's paper, governance questions of vital importance stand out.

Collectively, the four pieces present an insightful snapshot of how some of our leading scholars are thinking about the environmental challenges of the day. The

22 Gillespie, n. 11 above.

23 Ibid., at p. 171.

24 For more information, see: http://www.iucn.org/about/union/members/who_members.

25 Ibid.

26 See Art. 17(3)(b)(ii) of Directive 2009/28/EU on the Promotion of the Use of Energy from Renewable Sources [2009] OJ L140/16.

27 Gillespie, n. 11 above, at p. 176.

28 UNESCO Convention concerning the Protection of the World Cultural and Natural Heritage, Paris (France), 23 Nov. 1972, in force 17 Dec. 1975, available at: http://portal.unesco.org/en/ev.php-URL_ $\mathrm{ID}=13055 \&$ URL_DO=DO_TOPIC\&URL_SECTION=201.html. 
common thread that runs through the four pieces is that each author is seeking to illuminate the rules, processes and norms that can be observed in a particular issue area and, in doing so, is eschewing the hegemony of realism which belittles the importance of international law as a mere tool of power politics, as well as the straitjacket of legal positivism which can only shed so much light on how international law actually operates by focusing on 'what the law is'. The transnational rubric is useful and relevant but, at the same time, there is much room for clarification of the boundaries of the discourse and its methodological approaches. As editors, we look forward to supporting and witnessing efforts to enhance our collective knowledge of transnational environmental law.

Jolene Lin and Joanne Scott Editors 